\section{A STUDY OF THE PROBABILISTIC STATES OF MACHINE- TRACTOR AGGREGATES FOR WHEAT CULTIVATION}

\author{
Dragomir Dragoev, Krasimir Krastev, Krasimira Georgieva \\ Faculty of Technics and Technologies of Yambol, Trakia University, Bulgaria \\ Graf Ignatiev 38, 8600 Yambol, Bulgaria \\ e-mail:drago_dr13@abv.bg
}

\begin{abstract}
This paper applies Markov's theory of stochastic processes (Graph theory) to identify the probability of the machine-tractor aggregate being in each of the machine states adopted by the model. It features a graph of the states of a machine-tractor aggregate (Machine-status) operating in plant growing that allows us to determine the probability of the aggregate being in any of the states considered as basic. It proves that with the increase in the level of reliability of the aggregate, in this case its flawless performance, represented by the non-intermittent operation time indicator (time for trouble-free work), the probability that the aggregate will be in a functional state increases.
\end{abstract}

Keywords: Agriculture machinery, Machine status, Time for trouble-free work, Graph theory.

\section{INTRODUCTION}

For the sake of the mathematical explanation of each aggregate in plant agriculture we can present it in the form of a physical system, the state of which changes discretely and continuously over time in a random manner. The process of modifying the aggregate state corresponds to the methods of calculating the operations $[1,4,6,7]$ and can be presented as a sequence of states.

The aim of this study is to determine the probability of the machine-tractor aggregate in the course of the technological operations for wheat farming, being in each of the states adopted in the model using the apparatus of Markov's theory of stochastic processes (Graph theory).

\section{EXPOSURE}

Figure 1 shows a graph of the states of the aggregate and the possible state transitions are illustrated with arrows.

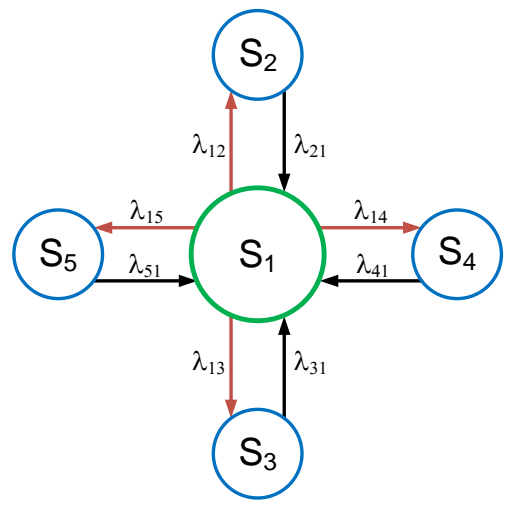

Figure 1. Graph of the states of machine-tractor aggregates

We assume that the aggregate goes from one state to another under the influence of consecutive random events. Generally, the aggregate can be in the following states: - $S_{1}$ upright, operating; $\mathrm{S}_{2^{-}}$malfunctioning, malfunction to be identified and fixed; $\mathrm{S}_{3}$ - performing

IRTIIL Vol. 6, No. 2, 2018 ISSN 1314-8788 (print), ISSN 1314-8796 (online), doi: 10.15547/artte.2018.02.001 


\section{AR'TIE \\ ( \\ Ipplied Researrorches in Technics, Technologies and Bductition \\ Journal of the Faculty of Technics and Technologies, Trakia University https://sites.google.com/a/trakia-uni.bg/artte/}

a turn; $\mathrm{S}_{4}$ - technological servicing is taking place (e.g. loading consumables or unloading of the grain tank, etc.); $S_{5}$ - technological malfunctions are being fixed.

The number of states depends on the type of aggregate, the type of technological process (plowing, sowing, plant protection, fertilizing, spraying, harvesting, etc.), the operation conditions, etc.

The average time for flawless operation (Time for trouble-free work) of the unit is represented by $t_{1} ; t_{2}$ is the time for search and troubleshooting; $t_{3}$ is the time to make a turn; $t_{4}$ is the technological maintenance time; $t_{5}$ is the time for fixing any technological flaws.

If we know the aggregate's average time of idleness in each of the above states, we can determine the probabilities of the latter by applying Markov's theory of stochastic processes.

In this case, the probability of stopping the aggregate to fix a flaw is $\alpha_{1}$, for making a turn $\alpha_{2}$, for maintenance $-\alpha_{3}$, and the probability $1-\left(\alpha_{1}+\alpha_{2}+\alpha_{3}\right)$ will reflect the intensity of transition from one state to another;

$$
\begin{aligned}
\lambda_{15}= & \frac{1-\left(\alpha_{1}+\alpha_{2}+\alpha_{5}\right)}{t_{1}} ;- \text { Intensity of transition from state } \mathrm{S}_{1} \text { to state } \mathrm{S}_{5} ; \\
\lambda_{12} & =\frac{\alpha_{1}}{t_{1}} ;- \text { Intensity of transition from state } \mathrm{S}_{1} \text { to state } \mathrm{S}_{2} ; \\
\lambda_{21} & =\frac{1}{t_{2}} ;- \text { Intensity of transition from state } \mathrm{S}_{2} \text { to state } \mathrm{S}_{1} ; \\
\lambda_{14} & =\frac{\alpha_{15}}{t_{1}} ;- \text { Intensity of transition from state } \mathrm{S}_{1} \text { to state } \mathrm{S}_{4} ; \\
\lambda_{41} & =\frac{1}{t_{4}} ;- \text { Intensity of transition from state } \mathrm{S}_{4} \text { to state } \mathrm{S}_{1} ; \\
\lambda_{13} & =\frac{\omega_{2}}{t_{2}} ;- \text { Intensity of transition from state } \mathrm{S}_{1} \text { to state } \mathrm{S}_{3} ; \\
\lambda_{31} & =\frac{1}{t_{4}} ;- \text { Intensity of transition from state } \mathrm{S}_{3} \text { to state } \mathrm{S}_{1} ; \\
\lambda_{51} & =\frac{1}{t_{5}} ;- \text { Intensity of transition from state } \mathrm{S}_{5} \text { to state } \mathrm{S}_{1} ; \\
\frac{d P_{2}}{d t} & =\frac{\alpha_{1} P_{1}}{t_{1}}-\frac{P_{2}}{t_{2}} ; \\
\frac{d P_{4}}{d t} & =\frac{\alpha_{3} P_{1}}{t_{1}}-\frac{P_{4}}{t_{4}} ; \\
\frac{d P_{3}}{d t} & =\frac{\alpha_{2} P_{1}}{t_{1}}-\frac{P_{3}}{t_{3}} ; \\
\frac{d P_{5}}{d t} & =\frac{\left(1-\alpha_{1}-\alpha_{2}-\alpha_{3}\right) P}{t_{1}}-\frac{P_{5}}{t_{5}} ;
\end{aligned}
$$

Once selected the state graph, we can determine all probabilistic states as time functions. These probability states satisfy the Kolmogorov - Chapman differential equation and are compiled by a common general rule $[1,6]$.

Then the system of differential equations of the states will look as follows:

The normative condition is:

$$
\begin{gathered}
P_{1}+P_{2}+P_{3}+P_{4}+P_{5}=1 ; \\
\text { or } \sum_{i=1}^{n} P_{i}=1 ;
\end{gathered}
$$

IRTTE Vol. 6, No. 2, 2018 ISSN 1314-8788 (print), ISSN 1314-8796 (online), doi: 10.15547/artte.2018.02.001 


\section{ARTITE}

Ipplied Researl'ches in Technics, Technologies ind Bducation

Journal of the Faculty of Technics and Technologies, Trakia University https://sites.google.com/a/trakia-uni.bg/artte/

When $t \rightarrow \infty$ the system is in stationary mode of operation. In order to calculate the marginal states, the left parts of the differential equations are set equal to zero and the result is a system of linear equations:

$$
\mid \begin{aligned}
& \frac{\alpha_{1} P_{1}}{t_{1}}-\frac{P_{2}}{t_{2}}=0 ; \\
& \frac{\alpha_{3} P_{1}}{t_{1}}-\frac{P_{4}}{t_{4}}=0 ; \\
& \frac{\alpha_{2} P_{1}}{t_{1}}-\frac{P_{3}}{t_{3}}=0 ; \\
& \frac{\left(1-\alpha_{1}-\alpha_{2}-\alpha_{3}\right) P}{t_{1}}-\frac{P_{5}}{t_{5}}=0 \\
& P_{1}+P_{2}+P_{3}+P_{4}+P_{5}=1 ;
\end{aligned} ;
$$

where $\alpha_{1}=\frac{t_{2}}{t_{2}+t_{3}+t_{4}+t_{5}}, \alpha_{2}=\frac{t_{3}}{t_{2}+t_{3}+t_{4}+t_{5}}, \alpha_{3}=\frac{t_{4}}{t_{2}+t_{3}+t_{4}+t_{5}}$;

We solve the system of equations and we find the value of probability $P_{1}$ by using the following formula:

$$
P_{1}=\frac{t_{1}}{t_{1}+\alpha_{1} t_{2}+\alpha_{2} t_{3}+\alpha_{3} t_{4}+\left(1-\alpha_{1}-\alpha_{2}-\alpha_{3}\right) t_{5}} ;
$$

And then the rest of the probabilities P1, P2, P3, P4 and P5 are calculated in the same manner.

$P_{1}$ - the probability of MTA being in a workable state, ie state $S 1$ (upright),

and then the other probabilities.

$\mathrm{P}_{2}$ - MTA incapacitated, malfunctions detected and removed.

$$
P_{2}=\frac{\alpha_{1} t_{2}}{t_{1}+\alpha_{1} t_{2}+\alpha_{2} t_{3}+\alpha_{3} t_{4}+\left(1-\alpha_{1}-\alpha_{2}-\alpha_{3}\right) t_{5}}
$$

$P_{3}-$ MTA performs a turn;

$$
P_{3}=\frac{\alpha_{2} t_{3}}{t_{1}+\alpha_{1} t_{2}+\alpha_{2} t_{3}+\alpha_{3} t_{4}+\left(1-\alpha_{1}-\alpha_{2}-\alpha_{3}\right) t_{5}}
$$

$\mathrm{P}_{4}$ - performing technological service of MTA;

$$
P_{4}=\frac{\alpha_{3} t_{4}}{t_{1}+\alpha_{1} t_{2}+\alpha_{2} t_{3}+\alpha_{3} t_{4}+\left(1-\alpha_{1}-\alpha_{2}-\alpha_{3}\right) t_{5}}
$$

$P_{5}$ - remove MTA techno malfunctions.

$$
P_{5}=1-\left(P_{1}+P_{2}+P_{3}+P_{4}\right)
$$

Figure 2 graphically represents the effect of the change in the flawless Time for trouble-free work $t_{1}$ (within $\pm 10 \%$ of its average value) on the probabilistic state of the machine $P_{1}$. Therefore, the increase in the level of the reliability of the aggregate, in this case its flawless performance, represented by the non-intermittent operation time indicator.

IRTIIE Vol. 6, No. 2, 2018 ISSN 1314-8788 (print), ISSN 1314-8796 (online), doi: 10.15547/artte.2018.02.001 


\section{ARTTIE Y}

Ipplied Researrches in Technics, Technologies ind Bduration Journal of the Faculty of Technics and Technologies, Trakia University https://sites.google.com/a/trakia-uni.bg/artte/

Figure 3 graphically presents the effect of the changes in the time spent on search and troubleshooting $t_{2}$ (within $\pm 10 \%$ of its average value) on the probabilistic state of the machine $\mathrm{P}_{1}$.

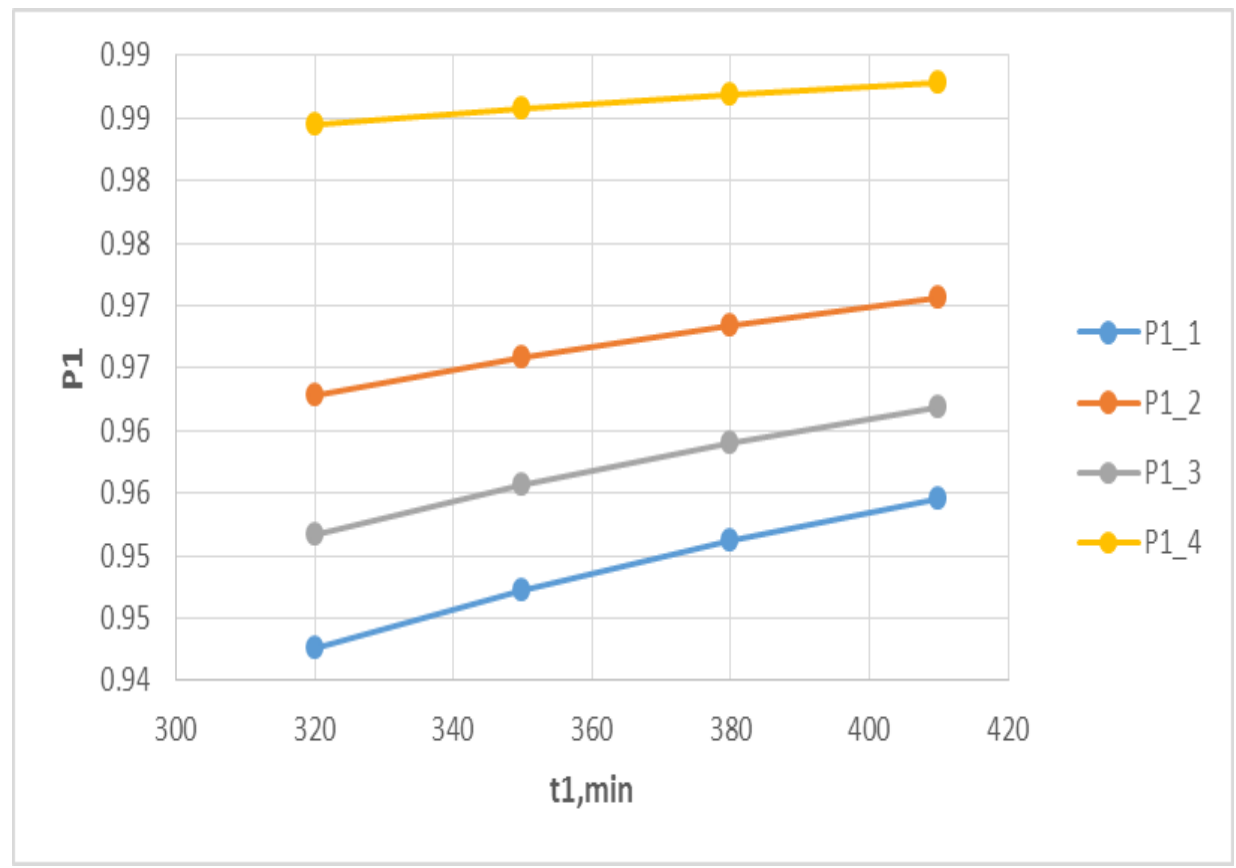

Figure 2. Effect of flawless non-intermittent operation time $t_{1}$ on $P_{1}$

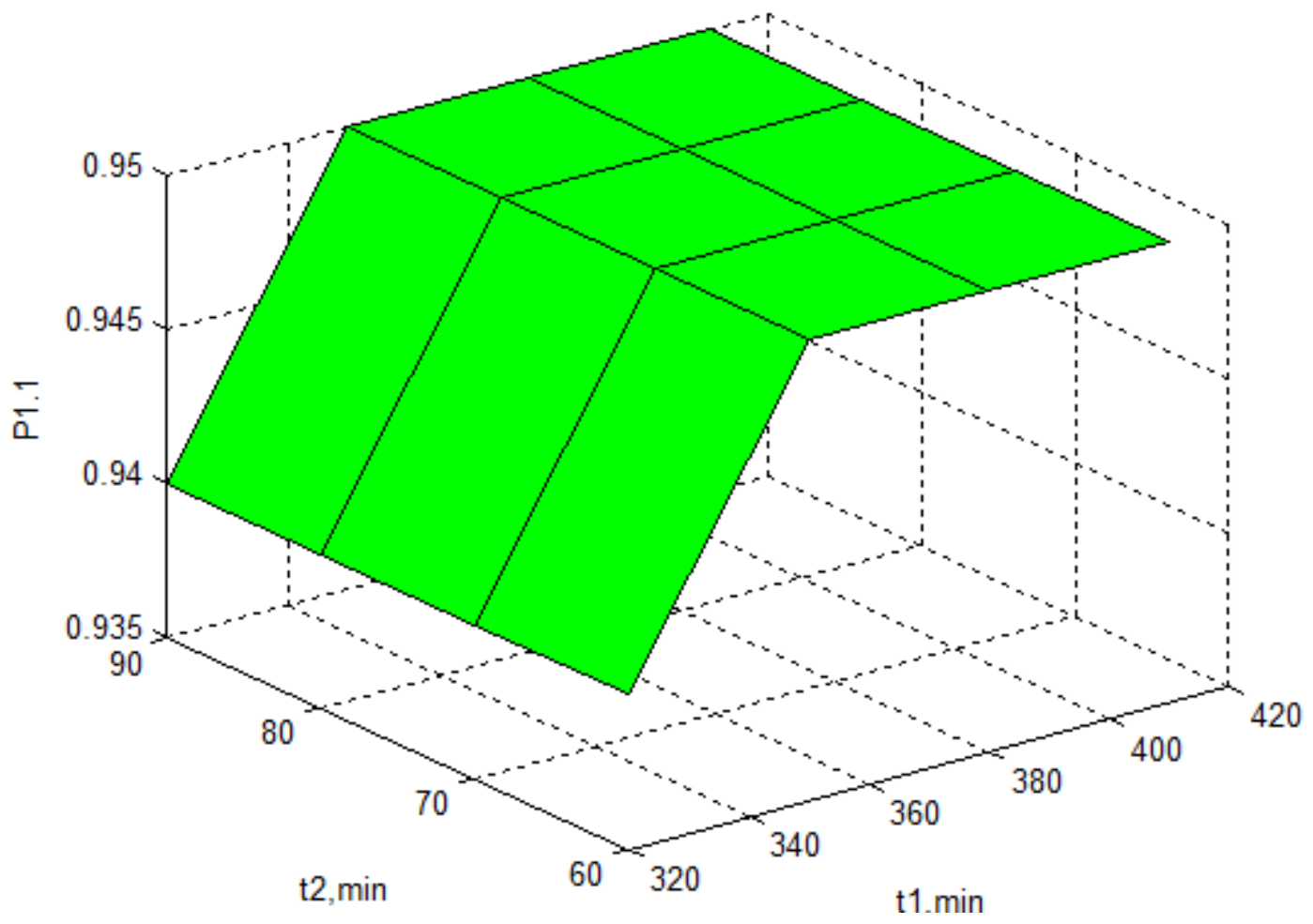

Figure 3. Changes in the probability of the unit being in a workable condition depending on the uninterrupted operation time $t_{1}$ and the search and troubleshooting $t_{2}$

IRTIIE Vol. 6, No. 2, 2018 ISSN 1314-8788 (print), ISSN 1314-8796 (online), doi: 10.15547/artte.2018.02.001 


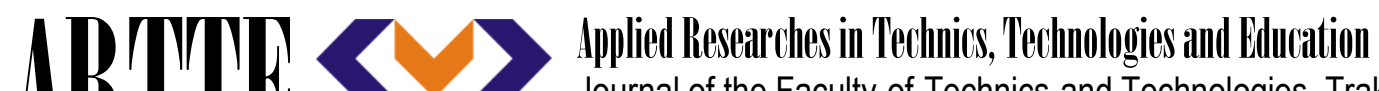 Journal of the Faculty of Technics and Technologies, Trakia University https://sites.google.com/a/trakia-uni.bg/artte/}

\section{CONCLUSION}

- This paper introduces a graph of the states of a machine-tractor unit operating in plant growing, which allows to determine the probability of the aggregate being in any of the states considered as basic.

- It proves that the increase in the level of reliability of an aggregate, in this case its flawless performance, presented by the non-intermittent operation time indicator (time for trouble-free work), increases the probability of the aggregate being in a functional state.

- A correlation has been established between the probability that the unit is in an operational condition and the times for flawless non-intermittent operation $t_{1}$ and for searching and troubleshooting $\mathrm{t}_{2}$.

\section{ACKNOWLEDGMENTS}

This research has been carried out under FTT/ 30.04.2015 project "Research and Optimization of the Parameters of a Logistic System for Agricultural Machinery Service " and is a part of a dissertation paper.

\section{REFERENCES}

[1] Venttsel E. S. Research on operations, Moscow, 1972 (in Russian).

[2] Mitkov A. M. Statistical methods for research and optimization of agricultural technics part 1, Sofia, 1980 (in Bulgarian).

[3] Ovcharov L. Applied problems of queuing theory, Moscow, 1979 (in Russian).

[4] Chuev Ju et al. Fundamentals of military operations research, Moscow, 1999 (in Russian).

[5] Tasev G. Statistical methods in scientific research, Sofia, 2008 (in Bulgarian).

[6] Tasev G. Statistical methods in scientific research, Sofia, 2009 (in Bulgarian).

[7] Zlatev Z., A. Dimitrova, T. Pehlivanova, P. Duchev. Energy efficiency of electric drive systems and its application in education, ARTTE Vol.4, No.1, 2016, ISSN 1314-8796, doi: 10.15547/artte.2015.04.004, pp. 21-28. 